\title{
40 anos da Pós-graduação da EEFE-USP \\ aos olhos de um docente pioneiro compromissado com a cientificidade e a gestão da educação física e esporte
}

http://dx.doi.org/10.11606/1807-55092017000nesp055

A presente contribuição à revisão histórica da "Pós-graduação "Stricto Sensu" da Escola de Educação Física e Esporte da Universidade de Sáo Paulo" por ocasião de seu $40^{\circ}$ aniversário de fundação, pretende pôr em evidência fatos de memória relacionados a significados e repercussóes deste programa e da disciplina nele incluída sob o título de "Administração da Educação Física e Esporte". Para tal tarefa, focalizarei experiências e impactos na minha qualidade de docente pioneiro do curso em pauta e no contexto da Educação Física e do Esporte no Brasil, principalmente com relação aos anos de 1970 e de 1980.

\section{Preliminares do pioneirismo}

Em retrospecto, antes da inauguração do Mestrado EEFE-USP em 1977, recebi no Rio de Janeiro, onde eu residia, a visita de Mario Nunes de Souza, Jarbas Gonçalves e Moacyr Daiuto, com um convite para integrar o corpo docente do mestrado que seria o primeiro do Brasil e da América Latina, na nossa área de dedicação comum da Educação Física e Esporte. Tomei conhecimento então que aqueles três reconhecidos líderes originários da EEFE-USP estavam mobilizando docentes com títulos acadêmicos exigidos pelo Ministério da Educação e Cultura (MEC) para a atuação na docência dos cursos "stricto sensu". A expressão 'mobilização', no caso, ganha aqui sentido apropriado diante de carência de mestres e doutores no nosso âmbito profissional à época, ainda sem tradiçóes na formação em pós-graduação.

A procura de docentes habilitados estava acontecendo em São Paulo e no Rio de Janeiro e nesta última cidade, além de minha pronta adesão, houve aceites por parte de Fernanda Barroso Beltrão, Manoel Gomes Tubino
Lamartine Pereira DaCOSTA*

Como antecedente, cumpre enfatizar que a minha compreensão sobre 'disciplina' em mestrados e doutorados consiste em uma construção coletiva de saberes - incluindo estudos e pesquisas de seu titular, docentes colaboradores e alunos - que se situa além de uma simples delimitaçáo de conhecimentos.

Por esse viés conceitual entende-se também que os impactos de uma disciplina sejam discernidos pela linha do tempo de suas atualizaçóes ou inércias, criando outrossim meios de observaçáo do programa que ela se incorpora vis-á-vis a área profissional que o referencia. Assim disposto, pretendo re-avaliar a disciplina "Administração" e o Mestrado EEFE-USP no contexto maior da Educação Física e esporte no país.

e Alfredo Gomes de Faria Júnior, todos professores renomados e capacitados à futura homologação do MEC. Mas no meu caso em particular, foi adotada a alternativa da titulação de "notório saber" pelos três organizadores do novo mestrado, procedimento legal para pré-habilitação de professores sem a titulação exigida mas com experiência em docência em pósgraduação "stricto sensu".

Esse dispositivo emergencial tornara-se comum na década de 1970 diante da grande expansão dos mestrados e doutorados no Brasil, em especial nos Estados de São Paulo e do Rio de Janeiro. E assim sendo, minha experiência - aparentemente a de maior significado no então nascente Mestrado EEFE-USP - já incluía a docência no Mestrado em Educação, disciplina de Metodologia Científica, em 1971, na PUC-Rio; a função de professor conferencista no Mestrado em Educação, disciplina de Teoria Geral de Sistemas, em 1972-1974, na UFRJ e na mesma universidade, Instituto de Geociências, no Mestrado de Geografia, também na disciplina de Teoria Geral
*Instituto de Educação Física e Desportos, Universidade do Estado do Rio de Janeiro, Rio de Janeiro, RJ, Brasil. 
de Sistemas, no mesmo período; e finalmente, a posição de professor titular na disciplina de Teoria Geral de Sistemas, Mestrado em Educaçáo, Fundação Getúlio Vargas - Rio de Janeiro, em 1974.

Tais credenciais certamente poderiam fortalecer o novo mestrado em seu ponto de partida e com este propósito Mario Nunes de Souza e Jarbas Gonçalves - já possuidores do título de doutor e respectivamente "presidente e vice-presidente" (sic) iniciais do curso em lide - me propuseram a docência da disciplina então denominada de "Administração da Educação Física e Esporte", embora já comprometida para ser assumida por José Guilmar de Oliveira, dos quadros da EEFE-USP na graduação, após ele obter o grau de doutor no exterior como se planejava à época.

Do meu ponto de vista, este arranjo pareceu aceitável pois meus empreendimentos em curso ganhariam uma ainda inédita base de desenvolvimento na área de Educação Física, em que se situavam minhas raízes profissionais; outra razão era a motivação extra para meu doutoramento, um requisito já posto no meu horizonte devido a uma carreira nascente em programas de pós-graduação "stricto sensu". Importa considerar nessas circunstâncias que o sentido de renovação da Educação Física e esporte à luz do conhecimento científico em geral, já residiam em meu portfólio desde o final dos anos de 1960 como ao longo da década de 1970.

Neste estágio da linha do tempo eu participara como editor do livro coletivo "Introdução à Moderna Ciência do Treinamento Desportivo"1 e logo após fui responsável pela elaboraçáo do livro "Diagnóstico de Educação Física e Desportos no Brasil"2. Embora ambas as obras possam ser consideradas como geradoras de impulsos renovadores, a primeira lançada em 1968 teve impacto relevante e imediato pois em três anos deu condiçóes para a criação ou remodelação da disciplina "Treinamento Esportivo" em todas as faculdades de Educação Física do país ${ }^{3}$ (p.13.134).

Este efeito singular à época pode ser creditado à ênfase posta na ciência e na produção de pesquisas por autores que as promoviam, então reunidos para a produção do livro, destacando-se Mauricio Rocha, Maria Lenk, Lamartine DaCosta, Luiz dos Santos, Mário Cantarino, Athaíde Ribeiro entre outros.

\section{Atualização do conhecimento da administração da educação física e esporte}

Mas ainda em retrospectiva, permito-me propor que o ponto de partida para a compreensão da mudança de sentido e conteúdo da administração da Educação Física e Esporte - hoje modernizada pela expressão "gestão" - teve lugar durante a elaboração do "Diagnóstico" de 1971. Nesta ocasião elegeu-se a Teoria Geral de Sistemas (TGS) como suporte teórico e metodológico para a coleta de dados em escala nacional das atividades físico-esportivas em suas variadas manifestaçóes. Por sua adequação a múltiplos e inter-relacionados ramos científicos, a TGS transitava naquele estágio no plano internacional como "mainstream" de aplicaçóes avançadas em pesquisas das áreas sociocultural, educacional, ecológicas e tecnológicas, destacando-se neste contexto as então chamadas "Ciências da Administraçâa"’2 (p.9-42).

Em resumo, a TGS definia-se como interdisciplinar, reconhecendo e dimensionando partes em um todo, procurando relacionamentos de entrada ("input") e saída ("output"), quer quantitativos como qualitativos. Historicamente a TGS, originava-se na Biologia, incorporando após a Segunda Guerra Mundial diferentes áreas de conhecimento e se integrando à tecnologia desde a década de 1950. E uma das suas versóes, sob a denominação de System Dynamics desenvolvida por Jay ForRESTER ${ }^{4}$ do famoso Laboratório MIT dos EE.UU., foi adotada com sucesso na indústria aeroespacial dos anos 1960, na gestão de empresas e em projetos de pesquisa na nascente área de informática além de acompanhamento do desenvolvimento urbano de grandes cidades.

O uso da TGS na linha de Forrester como meio de mapeamento das atividades físicas educacionais, esportivas e de lazer ativo no Brasil para posterior coleta de dados ${ }^{2}$ (p.353-9) foi por mim adotado quando atuava como especialista em Educação Física no Instituto de Pesquisa Econômica Aplicada - IPEA, com sede no Rio de Janeiro e Brasilia, contratado para elaborar o "Diagnóstico". Neste período o IPEA dedicava-se à montagem de 
diagnósticos multisetorias em escala nacional (energia, indústria, agricultura, educação etc), incluindo por consequência o da Educação Física e seus desdobramentos nos anos de 1969 e 1970.

A opção Forrester me atraiu durante a construção do modelo para o "Diagnóstico", especialmente pelos "frameworks" encontrados no livro Urban Dynamics (Forrester, 1969), que no IPEA passava de mão em mão entre os técnicos, destacando-se os consultores estrangeiros. Em anos posteriores, demonstrou-se o acerto da escolha pois a metodologia interdisciplinar de Forrester foi a dominante nos estudos pioneiros sobre o colapso em progresso do meio ambiente em escala planetária (Vide por exemplo The Limits to $G$ rowth ${ }^{6}$ ), uma abordagem até hoje válida e em contínuo fortalecimento.

Não constituiu surpresa, portanto, a minha vinculação pós-IPEA como docente em mestrados da UFRJ, PUC-RJ e FGV-RJ, pois a experiência no lidar com metodologias inovadoras de pesquisa por múltiplos viéses disciplinares me levou a ocupar funçôes de docência com raros candidatos capacitados e atualizados. E se deslocando o foco para o Mestrado EEFE-USP, cabe pôr em registro que a experiência em pauta se ajustou plenamente à disciplina contratada com Mario Nunes de Souza e Jarbas Gonçalves; isto porque o conhecimento mais atualizado da Administração exterior ao Brasil convergia para uma perspectiva sistêmica com base em tratamento de dados e respectivos processos de decisão, em encaminhamentos similares ao modelo adotado pelo "Diagnóstico".

A convergência identificada, antes de minha vinculação formal ao novo mestrado, teve um suporte de conhecimentos avançados em Administração digno de registro por ter se tornado a referência de base da disciplina então em perspectiva. Tal apoio didático consistiu na elaboração de uma publicação técnica em língua portuguesa que abordava a Administração em geral à vista de possíveis utilizaçôes práticas na Educação Física e Esporte. Esta obra definiu-se a partir do estado da arte da área de conhecimento da nova disciplina, com base em autores internacionais destacando-se importantes nomes da TGS e incluindo naturalmente Jay Forrester.

Por ter um conteúdo todavia inédito no Brasil, a iniciativa de atualização foi incorporada pelo MEC, publicando em 1979 um manual de acesso livre sob a denominação de "Noções de Administração para Profissionais da Educação Física e dos Desportos"7. De fato, a nova publicaçáo representou um avanço na sua área de especialidade desde que esta mostrava-se presa a nexos estabelecidos nos anos de 1940 (verifique-se por exemplo em $\mathrm{LENK}^{8}$ ) que não tinham sido atualizados ao longo das décadas seguintes.

\section{Renovação da administração da educação física e esporte}

A iniciativa da publicação de 1979 em face aos compromissos de ensino e pesquisa no nascente Mestrado da EEFE-USP, fez-se todavia presente como um ato de renovação do conhecimento; este avanço hoje poderia ser interpretado como uma inovação atitudinal em que se pensa o novo para motivar o surgimento da renovação de teorias e de práticas. Contudo, a minha intenção era também a de criar condiçóes para a renovação da Administração da Educação Física e Esporte "per se", como aqui antes antecipado.

Em síntese, o impulso da renovação dos conhecimentos em gestão já se tinha sido manifestado quando em 1968 foi lançada a obra mencionada sobre Treinamento Esportivo. E naquela oportunidade, uma maior cientificidade era o alvo da atualizaçáo desde que na Educação Física e nos esportes ainda sobreviviam naquele período procedimentos meramente empíricos, sem fundamentação científica. Por esta razão, foi organizado em 1972 no Rio de Janeiro, um evento que consolidou os avanços da obra de 1968 por iniciativa da Academia do Conseil International du Sport Militaire - ACISM, entidade de destaque mundial entre profissionais do esporte, incluindo a área de Medicina do Esporte. Veja-se então o relato de Tubino \& DaCosta (Ibid., p. 13.134) sobre este acontecimento em que surgiram vínculos com a USP e o futuro mestrado aqui em revisão:
A ACISM estreitou os laços com os especialistas brasileiros, trazendo ao Brasil um naipe de prestígio internacional para um Seminário em 1972, que consolidou definitivamente o treinamento esportivo associado à medicina do esporte no país em termos acadêmicos. Neste evento além do próprio Cooper, estavam presentes Philip Rasch (EUA) da Cinesiologia, 
Raoul Mollet (Bélgica) do Treinamento Total, Lelio Ribeiro (Portugal) dos fundamentos do treinamento esportivo, Mauricio Rocha da fisiologia do exercício e Lamartine DaCosta que cobriu a parte de metodologia da pesquisa. Coincidentemente, o Seminário da ACISM-1972 no RJ marcou também a consolidação dos laboratórios de fisiologia do exercício da UFRJ (o primeiro especializado do país sob condução de Maurício Rocha), da UFRGS com Eduardo De Rose e da USP, com Maria Augusta Kiss, ambos presentes no Seminário.

De fato, nesse evento Maria Augusta Kiss e outros professores da USP integraram o grupo de quase uma centena de educadores físicos e médicos ligados ao esporte, reunidos em tempo integral com hospedagem em um único local (um centro de treinamento da Marinha Brasileira no Rio de Janeiro), com a finalidade de atualizar conhecimentos e discutir sobre possibilidades de um efetivo desenvolvimento no país da pesquisa - seguindo-se denominaçóes usadas no evento em treinamento esportivo, fisiologia do esforço e cinesiologia.

Assistiu-se em fase posterior a essa histórica congregação de futuros agentes de renovação basicamente originados de RJ, SP, RS, PR e MG - a um crescimento contínuo e substancial da pesquisa em atividades físicas, destacando-se no caso a USP (Maria Augusta P.D. Kiss), a UFRGS (Eduardo De Rose) e a UFMG (Sylvio Raso) com seus laboratórios pioneiros, além do já instalado na UFRJ (Mauricio Rocha) em operação desde meados da década de 1960. O reconhecimento deste avanço encontra-se "inter alia" em Tubino e DACosta ${ }^{3}$ (p.13.134) com relatos sobre repercussóes que se estenderam às décadas seguintes.

Entretanto com relação ao "Laboratório de Fisiologia do Exercício” (sic), sob direção de Maria Augusta Kiss desde 1976 - primeiramente localizado na graduação da EEFE-USP -, cabe pressupor que além de representar avanços na sua área de especialização, este meio operacional se tornou um dos vetores para o desenvolvimento do Mestrado "Stricto Sensu". Comprova-se esta assertiva, revisando-se dados do inventário de dissertaçóes do Mestrado EEFE-USP, produzido por Alberto Carlos Amadio ${ }^{9}$ e referido ao período 1979-1989, em que se constata que $10 \%$ dos novos mestres ( $\mathrm{n}$ = 100) foram orientadas por Maria Augusta Kiss.

Neste mesmo levantamento, verifiquei que $28 \%$ das dissertaçóes relacionavam-se a conteúdos da Medicina do Esporte e da Biomecânica (denominação do inventário), o que demonstra que o Mestrado EEFE-USP - quer pelo seu laboratório ou pelos seus orientadores - já se tornara um dos marcos da renovação científica em sua fase pioneira e no contexto da Educação Física e esporte.

\section{Repercussões da disciplina de administração no mestrado EEFE-USP e na sua área de conhecimento}

Também por meio do inventário Amadio 9 envidencia-se que $38 \%$ das dissertações vinculavamse à Pedagogia em suas diversas versóes da aprendizagem motora, da aptidão física, da metodologia de ensino e de outras formas de intervenção e de caracterização, conferindo uma identidade renovadora ao Mestrado EEFE-USP a partir da Educação Física tradicional. Os avanços dos saberes da tradição, porém, mostravam-se evidentes em face aos conteúdos dos resumos das dissertaçóes inventariadas, em que dominavam critérios de medição e interpretações quantitativas.

De modo idêntico verificou-se com relação ao Treinamento Esportivo (métodos, qualidades física, aplicaçóes em modalidades esportivas etc) que agregou $25 \%$ das dissertaçôes, como também num agrupamento menor de defesas com foco na Sociologia e nas Ciências de Comunicação, que somam 6\% das dissertações. Por seu turno, a Administração estratificou-se entre as defesas, com 3\% das opçóes.

Em síntese, o Mestrado EEFE-USP em suas 100 primeiras dissertaçóes correspondeu no meu entender ao que se esperava dele em termos de pesquisas e de formação profissional, seguindo-se os critérios do MEC então correntes. Também do ponto de vista de contribuição aos saberes típicos da Educação Física e esportes, os $63 \%$ das dissertaçóes de conteúdos pedagógicos e de Treinamento Esportivo confirmam a já aqui identificada renovação a partir das tradiçóes da área.

Afora o contexto de impactos renovadores do programa pioneiro da EEFE-USP, a reduzida opção 
pela Administração da Educação Física e Esportes solicita verificaçóes. Eis que se revela primeiramente a impossibilidade do titular inicial da disciplina - autor de presente ensaio - participar do programa como orientador já que se tratava de função outorgarda a doutores. Fui, neste sentido, docente pioneiro do Mestrado EEFE-USP mas com reduzida participação na sua consolidação em seus primeiros anos de existência. Minha vinculação à disciplina ocorreu em 1977 e depois em 1980, com José Guilmar de Oliveira assumindo-a em 1981, ao retornar de seu doutoramento na University of Oregon.

Outra razão da pouca adesão à disciplina por meio de dissertaçóes - isto é, por pesquisas orientadas - no período 1979-1989 foi a escassez de orientadores com interesse na temática da Administração. Recorrendo-se ao inventário AMADIO ${ }^{9}$ observa-se que os primeiros orientadores apresentaram-se dispersos no programa desde que somavam 32 para atenderem 100 dissertaçóes; ou seja, a média de defesas por orientador mostrou-se igual a 3, quantitativo inclusive alcançado por José Guilmar de Oliveira, titular da disciplina no período em foco, i.e. 1981-1989.

Os dados citados sobre orientadores, por outro lado, são coerentes com os conhecimentos de maior trânsito no programa; assim Maria Augusta Kiss foi responsável por 10 defesas - como antes aqui registrado - seguindo-se Go Tani com oito e de Moacyr Daiuto, Jarbas Gonçalves e Sergio Zucas, com sete, todos relacionados às áreas de Medicina do Esporte, Pedagogia ou Treinamento Esportivo (91\% das dissertaçóes no período). Como o restante dos orientadores se distribuíram entre cinco e uma defesas para cada um deles (com 10 marcando uma única defesa), importa supor que o programa em sua fase inaugural incorporou orientadores de várias origens - USP ou outras universidades - incluindo aqueles pertencentes à EEFE-USP que retornavam de doutoramento no Brasil ou no exterior.

Resumindo-se, a disciplina de "Administração da Educação Física e Esporte" na fase pioneira do mestrado em que estava inserida, teve um papel apenas de ruptura em potencial, com modestas repercussóes. Como tal, em diferença portanto das minhas expectativas originais, adveio apenas um suporte limitado de promoção dos conhecimentos renovados de gestão pois ao contrário do Treinamento Esportivo havia poucos vetores de transformação - docentes e discentes, interna e externamente ao programa - originados do conhecimento tradicional da área em lide. Em outras palavras, as três defesas e um orientador ativos na primeira década da existência do programa, em tese e numa visão atualizada nos dias presentes, representariam as proporçôes reais de importância da disciplina à época, estensivas à sua área de conhecimento e de intervençáo profissional e ao próprio Mestrado EEFE-USP.

É significativo considerar em face à tese de inovação em potencial, a repercussão "post hoc" da disciplina Administraçáo entre os mestrandos matriculados em 1977-1980. Sintomáticamente, por meio de consultas à Plataforma Lattes, constatou-se que apenas dois egressos pioneiros deste periodo - Otavio Fanali e Almir Liberato - em um grupo de oito identificados a partir das listagens nos inventários de Alberto Carlos AMAdIo ${ }^{9-12}$, incluíram no item "Área de Atuação" de seus currículos a opção "Administração". Esta vinculação nos dois casos incluía produção acadêmica orientada para a mesma temática nas décadas 19801990 , sendo que no primeiro egresso citado registrouse uma especialização na Universidade de Berlin no período 1984-1986.

Assinale-se por necessário que ambos exparticipantes da fase pioneira da disciplina em foco defenderam suas dissertaçóes em temas relacionados às dimensôes pedagógicas e esportivas da Educação Física - como se verifica também em AMAdio9 - , confirmando assim a influência menor dos assuntos de Administração no Mestrado EEFE-USP. Há também de se considerar adesóes posteriores por razōes extra USP pois a área de conhecimentos de gestão na Educação Física e esportes teve impulsos de desenvolvimento mais efetivos no Brasil a partir de meados da década de 1980, por iniciativas não necessariamente influenciadas pelas obras "Diagnóstico" de 1971 e "Noçôes de Administração" de 1979, como se toma conhecimento pelo estudo de Nolasco et al. ${ }^{13}$. 


\section{Cientificidade e interdisciplinaridade: passado e presente}

Na mesma linha de interpretação que privilegia agentes de inovaçáo independentes entre si quanto aos avanços da "Gestão da Educação Física e Esporte" (nomenclatura surgida na década 1990) no país, há que se posicionar o relato de Flávia Cunha Bastos que resgata fatos de memória da disciplina "Administração" no contexto do Mestrado EEFE-USP. Ela foi aluna deste programa entre 1981 e 1984 e atuou nos anos seguintes de modo intermitente em diversas funções na EEFE-USP como docente (Graduação, Bacharelado, Mestrado e atualmente no Doutorado), sempre na área de Gestão. E com base nestas experiências, ela sintetiza como matriz da disciplina a continuidade da oferta, em que pese mudanças de docentes vinculados incluindo o afastamento de José Guilmar de Oliveira por aposentadoria - e alteraçóes nos conteúdos, as quais desde o início dos anos 2000 tem apontado para a variedade de abordagens na temática da Gestão. Vejamos, entấo, as declaraçôes desta fonte emitidas em entrevista ${ }^{a}$ :

Na Pós-Graduação é oferecida por mim a disciplina para alunos de Mestrado e Doutorado, tanto da EEFE como de outras unidades da USP, com a denominaçáo de "Gestáo do Esporte: Organização, Legislação e Políticas”. Eu oriento alunos de Mestrado (4 concluídos e $4 \mathrm{em}$ andamento) e Doutorado (2 em andamento). O Prof. Ary José Rocco Júnior, também da Pós-Graduação, oferece a disciplina "Comportamento do Consumidor no Esporte" e orienta mestrandos (1 concluído e 7 em andamento). Na Graduaçáo sou responsável pela disciplinas "Dimensôes Econômicas e Administrativas da Educação Física e do Esporte" (Núcleo Básico) e "Legislação e Política no Esporte" (Bacharelado em Esporte). O Prof. Rocco Júnior é responsável pelas disciplinas "Marketing Esportivo", "Gestâo de Projetos e Eventos Esportivos" (optativas) e "Jornalismo Esportivo" (Bacharelado em Administração Esporte)- (Informaçāo pessoal).

Portanto, ao longo das décadas seguintes à fase pioneira, a disciplina em questáo encontrou uma vocaçâo mais voltada para aplicaçôes práticas do seu setor profissional, a julgar pelo perfil de sua oferta mais recente. A demonstração de tal procedimento, no meu entender, encontra apoio mais incisivo na concepção da linha de pesquisa "Gestão, Políticas, Marketing e Comunicação em Esporte e Educação Física", hoje desenvolvida respectivamente no Mestrado e Doutorado sob responsabilidade da declarante, como outrossim ela descreve com especificidades ${ }^{a}$ :

Estudo dos fundamentos da gestáo, da comunicação e do marketing esportivo visando desenvolver conhecimentos acerca dos processos nos segmentos de prática, de produção e de promoção, bem como em relação ao gestor esportivo, no âmbito da Educaçáo Física e do Esporte. Pressupóe a aplicaçáo de método científico, englobando coleta, análise e interpretação dos dados objetivamente ou subjetivamente, sobre características de indivíduos, grupos, organizaçôes, ideias, demográficas, pensamentos, modelos, teorias, a fim de obter novos conhecimentos, ou adicionar a base dos conhecimentos existentes do campo da gestão de organizaçôes, projetos e programas - (Informação pessoal).

Diante desta proposta, permito-me enfim postular que há no presente da disciplina de Gestão da Educação Física e Esporte da EEFEUSP direcionamentos similares aos de seu passado, uma vez que cientificidade com relaçóes de interdisciplinaridade, podem ser plenamente tipificadas tanto na proposta 2017 como na versão de 1977. Entretanto, é natural que haja tal convergência dado a que se trata de propósitos hoje universais da pesquisa científica com suas raízes nas solicitaçóes de renovação da década de 1970 pelo menos no referente à Educação Física e Esportes segundo as condiçóes encontradas no Brasil. Apenas como distinçôes entre passado e presente, argumentaríamos que as proposiçóes atuais focalizam preferencialmente ambientes e gruposalvo em que praticam suas intervençôes ao passo que no passado as inquiriçóes focalizavam com maior incidência a construção do conhecimento.

Deslocando as atençóes para o Mestrado EEFE-USP, a busca de nexos voltados para a cientificidade e a interdisciplinaridade na atuaçáo de seus docentes, tem se revelado por meio de arrazoados e nomenclaturas diferentes na linha do tempo, o que explica em princípio as escolhas programáticas de Flávia Bastos e associados. Como tal, esta peculiaridade - típica dos anos de 1990 no âmbito da EEFE-USP - no início dos anos 2000 foi analisada por mim e meus alunos de Epistemologia, 
no mestrado e doutorado de Educação Física da Universidade Gama Filho do Rio de Janeiro, onde então me vinculava, no qual interpretamos o debate promovido no âmbito da Pós-graduação "Stricto Sensu" de várias universidades e por diferentes pesquisadores à luz do significado teórico e prático da Educação Física ${ }^{14}$.

Em Go Tani, docente já aqui mencionado da EEFE-USP, por exemplo, encontramos teorizações sobre a Educação Física segundo suas formas de aplicação (prática) de ciências (teorias), a partir das novas oportunidades de emprego. Nesta abordagem pragmática o curso acadêmico poderia justificar-se vinculado à qualidade da preparação profissional, dependendo esta de um suporte de área definido e em desenvolvimento em termos científicos. Vejamos, então, um trecho da análise em que reinterpretamos a proposta do citado docente sobre a renovação da Educação Física como área de intervenção profissional ${ }^{14}$ (p.150):

Como esta disciplina tem adotado diferentes abordagens fisiológicas e psicológicas para se legitimar, formaram-se especializaçóes dentro do curso com implicaçóes tais como da formação de professores ligados à educação ou profissionais ligados ao mercado. Essas implicaçóes da especialização e fragmentação do conhecimento, bem como a escassez de pesquisas aplicadas, geraram subdisciplinas incorporadas ao currículo sem maiores questionamentos, resultando na formação de profissionais com capacidade analítica, mas com grandes dificuldades de sintetizar conhecimentos. Assim, Go Tani lança uma proposta que muda a nomenclatura da educação física para cinesiologia, definindo-se uma identidade e uma refutação acadêmica próprias. Ter-se-ia então uma área de conhecimento tendo como objeto de estudo o movimento humano, com foco nos movimentos genéricos (postura, locomoção, manipulação) e específicos de esporte, exercício, ginástica, jogo e dança. Em conseqüência, haveria uma metodologia de estudo especializada, abrangendo dos níveis mais microscópicos até os mais macroscópicos, transcendendo os limites das disciplinas tradicionais.

Como se pode discernir, a revisão a partir desses posicionamentos acadêmicos de Go Tani orientase para uma busca de cientificidade mais bem posicionada para a Educação Física e Esporte além de promover melhores relaçôes de interdisciplinaridade. E ao fim e ao cabo, a procura identificada no âmbito do Mestrado EEFE-USP nos anos 1990 repete as pretenções da disciplina pioneira em Gestão da Educação Física e Esporte no final da década de 1970 bem como antecipa-se às suas propostas da mesma disciplina nos anos 2000, já em nível de Mestrado e Doutorado na mesma instituição. Em suma, cientificidade e interdisciplinaridade constituem em potência e por experiência um fio condutor para aqueles que rememoram os 40 anos de existência do Mestrado EEFE-USP.

\section{Nota}

a. Bastos FC. Comunicação oral em 8 de mai. 2017.

\section{Referências}

1. DaCosta L. Introdução à moderna ciência do treinamento desportivo. Brasília: Divisão de Educação Física/MEC; 1968.

2. DaCosta L. Diagnóstico da educação física e desportos no Brasil. Brasília: FENAME; 1971.

3. Tubino MG, DaCosta L. Treinamento esportivo. In: DaCosta L, organizador. Atlas do esporte no Brasil. Rio de Janeiro: CONFEF; 2006. p.13.133-13.137. Disponível em: http://www.atlasesportebrasil.org.br/textos/315.pdf.

4. Forrester J. From the ranch to system dynamics: an autobiography. Greenwich: JAI Press; 1992. [citado 6 mai. 2017]. Disponível em: http://www.systemdynamics.org/DL-IntroSysDyn/origin.htm.

5. Forrester J. Urban dynamics. Portland: Productivity Press; 1969.

6. Meadowns D, et al. The limits to growth. New York: Universe Books; 1972.

7. DaCosta L. Noçóes de administração para profissionais da educação física e dos desportos. Brasilia: MEC/Departamento de Documentação e Divulgação; 1979. 
8. Lenk M. Organização da educação física e desportos. Rio de Janeiro: Imprensa Oficial; 1942.

9. Amadio AC. 100 dissertaçôes de mestrado. Rev Paul Educ Fís. 1990;4:11-137.

10. Amadio AC. Os caminhos da pós-graduação "stricto sensu”. Rev Paul Educ Fís. 1999;13:36-41.

11. Amadio AC. Trajetória da pós-graduação stricto sensu na Escola de Educação Física e Esporte da Universidade de São Paulo após 25 anos de produção acadêmica. Rev Bras Ciênc Esporte. 2003;24:27-47.

12. Amadio AC. Consolidação da pós-graduação "stricto sensu" da Escola de Educação Física e Esporte da Universidade de São Paulo: trajetória acadêmica após 30 anos de produção. Rev Bras Educ Fís Esporte. 2007;21(N. esp):25-36.

13. Nolasco VP, Bitencourt V, Paoli PB, Gomes E, Castro M. Administração/gestão do esporte. In: DaCosta L, organizador. Atlas do esporte no Brasil. Rio de Janeiro: CONFEF; 2006. p.18.92-18.93.

14. DaCosta L, Duarte CP. O debate epistemológico da educação física no âmbito dos cursos de pós-graduação stricto sensu reinterpretado por contribuiçôes da teoria da complexidade de Morin. Rev Bras Cienc Esporte. 2003;24:147-59.

\begin{tabular}{r|r} 
ENDEREço & Lamartine Pereira DaCosta \\
Programa de Pós-graduação em Ciências de Exercício e do Esporte & Universidade do Estado do Rio de Janeiro \\
R. São Francisco Xavier, 524 - 9. andar - Bl. F - sala 9122 & 20550-900 - Rio de Janeiro - RJ - BRASIL \\
e-mail: dacosta8@com.br & \\
\end{tabular}

62 • Rev Bras Educ Fís Esporte, (São Paulo). 2017 Ago; 31(N esp):55-62. 